\title{
GEMAS: Establishing geochemical background and threshold for 53 chemical elements in European agricultural soil.
}

Applied Geochemistry, 88, 302-318. 2018.

Reimann C, Fabian K, Birke M, Filzmoser P, Demetriades A, Negrel P, Oorts K, Matshullat J, Caritat P and the GEMAS Project Team, including Flight DMA and Scheib AJ.

Abstract

The GEMAS (geochemical mapping of agricultural soil) project collected 2108 Ap horizon soil samples from regularly ploughed fields in 33 European countries, covering 5.6 million $\mathrm{km} 2$. The $<2 \mathrm{~mm}$ fraction of these samples was analysed for 53 elements by ICP-MS and ICP-AES, following a HNO3/HCl/H2O (modified aqua regia) digestion. Results are used here to establish the geochemical background variation and threshold values, derived statistically from the data set, in order to identify unusually high element concentrations for these elements in the Ap samples. Potentially toxic elements (PTEs), namely $\mathrm{Ag}, \mathrm{B}, \mathrm{As}, \mathrm{Ba}, \mathrm{Bi}, \mathrm{Cd}, \mathrm{Co}, \mathrm{Cr}, \mathrm{Cu}, \mathrm{Hg}, \mathrm{Mn}, \mathrm{Mo}, \mathrm{Ni}, \mathrm{Pb}, \mathrm{Sb}, \mathrm{Se}, \mathrm{Sn}, \mathrm{U}, \mathrm{V}$ and $\mathrm{Zn}$, and emerging 'high-tech' critical elements (HTCEs), i.e., lanthanides (e.g., Ce, La), Be, Ga, Ge, In, Li and TI, are of particular interest. For the latter, neither geochemical background nor threshold at the European scale has been established before. Large differences in the spatial distribution of many elements are observed between northern and southern Europe. It was thus necessary to establish three different sets of geochemical threshold values, one for the whole of Europe, a second for northern and a third for southern Europe. These values were then compared to existing soil guideline values for (eco)toxicological effects of these elements, as defined by various European authorities. The regional sample distribution with concentrations above the threshold values is studied, based on the GEMAS data set, following different methods of determination. Occasionally local contamination sources (e.g., cities, metal smelters, power plants, agriculture) can be identified. No indications could be detected at the continental scale for a significant impact of diffuse contamination on the regional distribution of element concentrations in the European agricultural soil samples. At this European scale, the variation in the natural background concentration of all investigated elements in the agricultural soil samples is much larger than any anthropogenic impact. 